\title{
Caregiver Burden among Caregivers of Patient Undergoing Hemodialysis in Tertiary Care Center : A Descriptive Cross-sectional Study
}

\author{
Srijana Khatri Chhetri, ${ }^{1}$ Rojina Baral ${ }^{1}$ \\ 'Department of Nursing, College of Medical Sciences Bharatpur, Chitwan, Nepal.
}

\section{ABSTRACT}

Introduction: Chronic kidney disease affects almost all aspects of life of the patients and caregivers. Dialysis is a common treatment modality for chronic renal failure. The caregivers of patients undergoing hemodialysis bear the emotional and psychological stress of having a chronically ill patient. The physical and psychological distress, limitations in personal and social activities, loss of freedom, financial limitations directly or indirectly affect the level of burden among caregivers. This study aims to study the level of burden among caregivers of patient undergoing hemodialysis.

Methods: A descriptive cross-sectional study among 123 caregivers giving care to hemodialysis patients for at least 3 months at Teaching Hospitals, Chitwan was carried out using simple random sampling technique. Level of burden was evaluated using the burden questionnaire (Zarit Burden Interview).

Results: The study revealed that $60(48.78 \%)$ had mild to moderate, $53(43.08 \%)$ had moderate to severe. The median scores for burden among the caregivers was $(39.30 \pm 11.68)$ with $44.65 \%$.

Conclusions: CopingStrategies, socialsupport,supportinterventionshasgreaterimpactoncaregiversinachieving their roles in caring the patients and increases the capability to cope effectively with the patient's condition.

Keywords: burden; caregiver; hemodialysis.

\section{INTRODUCTION}

Hemodialysis is a treatment modality which contributes to the better physical condition of the patient by

preventing further complications due to uremia. ${ }^{1}$ According to Global Burden of Disease Study, kidney disease was the $12^{\text {th }}$ most common cause of death, accounting for 1.1 million deaths worldwide ${ }^{2}$ and as per World health ranking the death rate in Nepal in case of kidney disease is 21.72 per 100,000 and Nepal falls in 52nd rank among 183 countries. ${ }^{3}$

Patients on dialysis require caregiving and assistance in their daily lives from family members and others for hospital visitation and supervised administration which places a considerable burden on caregivers. ${ }^{4}$ The family burden is mainly caused by the combination of physical work, emotional pressure, social restrictions, and economic demands during the provision of care to their patients and this has been found to be associated with a significant reduction in caregivers' quality of life and their health status. ${ }^{5}$

Therefore, this study aims to study the level of burden among caregivers of patient undergoing hemodialysis.

\section{METHODS}

A descriptive cross-sectional study was carried among caregivers of patient undergoing hemodialysis at two Teaching Hospitals, Chitwan. Ethical Clearance was obtained from the Institutional Review Committee of College of Medical Sciences Teaching Hospital (COMS$\mathrm{TH})$. Written consent was obtained from each sample before collecting data. Data was collected by using

Correspondence: Rojina Baral, Department of Nursing, Bharatpur, Chitwan, Nepal. Email: rojina.baral@gmail.com, Phone: $+977-9845817996$. 
Simple random sampling technique. Random number table was used to collect a total of 123 samples. Sample size was calculated using the formula

$\mathrm{n}=\mathrm{Z}^{2,} \times \mathrm{p} \times \mathrm{q} / \mathrm{e}^{2}$

where $Z=1.96$ at $95 \%$, confidence interval

$$
\begin{aligned}
& p=\text { prevalence }, 49.4 \%^{13} \\
& q=1-p \\
& e=\text { margin of error }, 5 \%
\end{aligned}
$$

$\mathrm{n}=155$ and Non-response rate $=10 \%$.

And using Probability Proportion Size, 69 sample from COMS-TH and 54 samples from CMC-TH was collected. The data was collected from 12th May to 10th June, 2019 from both tertiary care center. Caregivers providing care to hemodialysis patients for at least 3 months and with no severe life events within past 3 months were selected for the study. Zarit Burden Interview was used as a tool to collect the data. Permission from Mapi Research Trust was obtained and validated version of Zarit Burden Interview in Nepali language was used for the study. Data obtained was reviewed, coded and entered in SPSS 23 version and the descriptive statistical analysis was done.

\section{RESULTS}

Among 123 caregivers, 71 (57.72\%) were female and remaining were male. Maximum participants 48 $(39.02 \%)$ were of age $20-39$ years whereas $6(4.87 \%)$ were of age $\leq 19$ years. Majority of the participants $52(42.27 \%)$ were illiterate, and among literates 32 $(26.01 \%)$ were having secondary level education. Most of the participants $69(56.09 \%)$ of them were spouse of patients. Similarly, $58(47.15 \%)$ of caregiver's time period of giving care to patient was more than 3 years. Also $51(41.46 \%)$ of the patients were hypertensive

\begin{tabular}{|c|c|c|}
\hline \multicolumn{2}{|c|}{$\begin{array}{l}\text { Table 1. Caregiver's } \\
\text { Characteristics. }\end{array}$} & \multirow{2}{*}{$\begin{array}{c}\text { Socio-demographic } \\
\mathrm{n}(\%)\end{array}$} \\
\hline S.N. & Demographic Variables & \\
\hline \multirow[t]{5}{*}{1.} & Caregiver's Age & \\
\hline & $<=19$ years & $6(4.87)$ \\
\hline & $20-39$ years & $48(39.02)$ \\
\hline & $40-59$ years & 46 (37.39) \\
\hline & $>=60$ years & $23(18.69)$ \\
\hline \multirow[t]{3}{*}{2.} & Sex & \\
\hline & Male & $52(42.27)$ \\
\hline & Female & $71(57.72)$ \\
\hline
\end{tabular}
and $58(47.15 \%)$ of patient's functional status was poor (Table 1 and 2). Education
Illiterate $52(42.27)$

Primary level education $19(15.44)$

Secondary level education $32(26.01)$

Higher secondary level 13 (10.56) education

Intermediate of post school

Diploma

Graduate or postgraduate

$3(2.43)$

Professional

4. Marital status

Single $16(13)$

Married $103(83.73)$

Widowed

Divorced/Separated

5. Occupation

Unemployed

Unskilled worker

Semi-skilled

Skilled worker

Clerk, Shop owner, Farm

Profession

$2(1.62)$

6. Type of family

Nuclear

Joint

7. Relationship with patient

Child

Parent

Sibling

$4(3.25)$

Spouse

69 (56.09) 


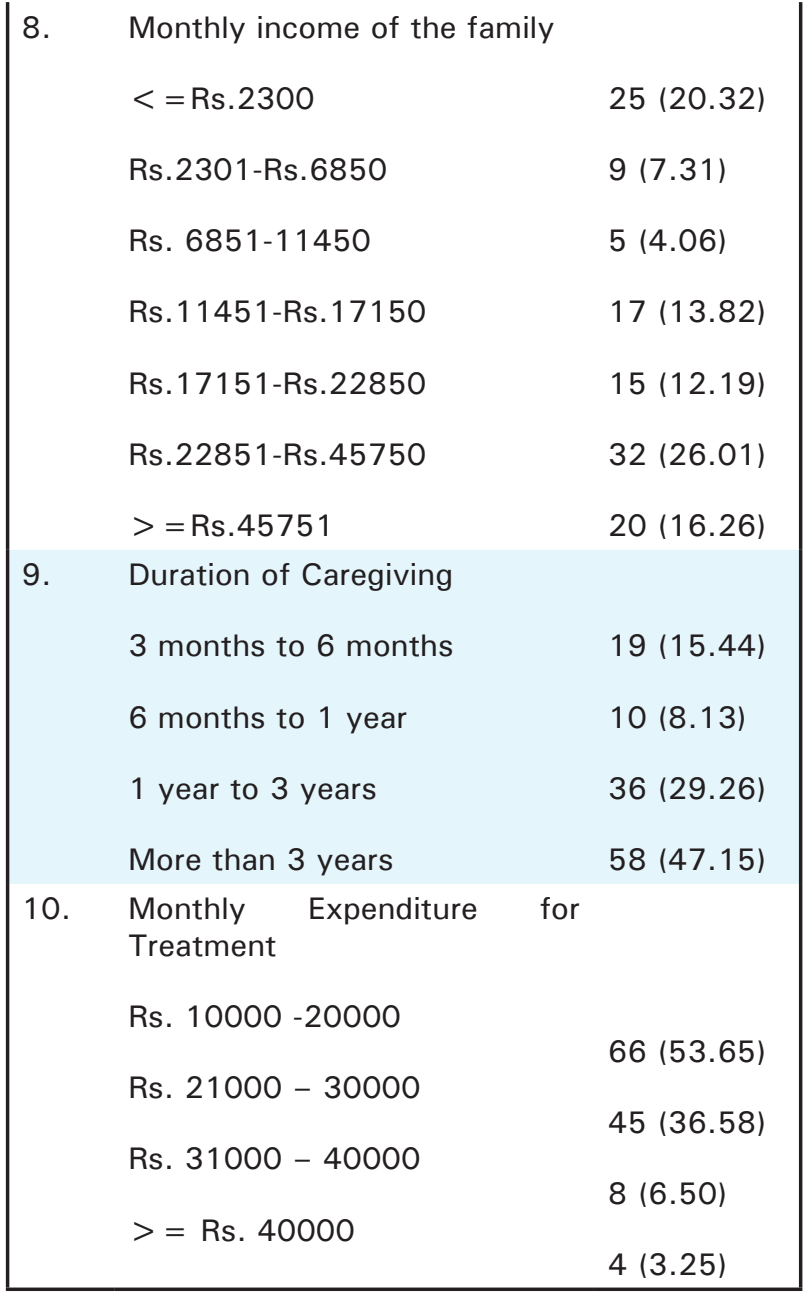

Table 2. Patient's Socio-demographic Characteristics.

S.N. Demographic Variables n (\%)

1. Patient's Age

$<=19$ years

$4(3.25)$

$20-39$ years

27 (21.95)

$40-59$ years

47 (38.21)

$>=60$ years

45 (36.58)

2. Sex

Male

70 (56.91)

Female

$53(43.08)$

3. Duration of Illness

3 months to 6 months

$13(10.56)$

6 months to 1 year

$9(7.31)$

1 year to 3 years

33 (26.82)

More than 3 years
4. Duration of Hemodialysis

3 months

3 months to 6 months

$24(19.51)$

6 months to 1 year

More than 1 year

$72(58.53)$

5. Comorbidities

Hypertension

$51(41.46)$

Diabetes

$8(6.50)$

Cardio Vascular Diseases

$8(6.50)$

Both $A$ \& B

$29(23.57)$

Others

$17(13.82)$

No any comorbidities

$10(8.31)$

6. Functional Status

Usually do with no difficulty 5 (4.06)

Does with some difficulty

$51(41.46)$

Does with more difficulty

$9(7.31)$

Usually do not do because of 58 (47.15) health condition

Majority of caregiver $60(48.78 \%)$ had mild to moderate burden and $53(43.08 \%)$ had moderate to severe burden (Figure 1). The overall mean burden score was $39.30 \pm 11.68$.

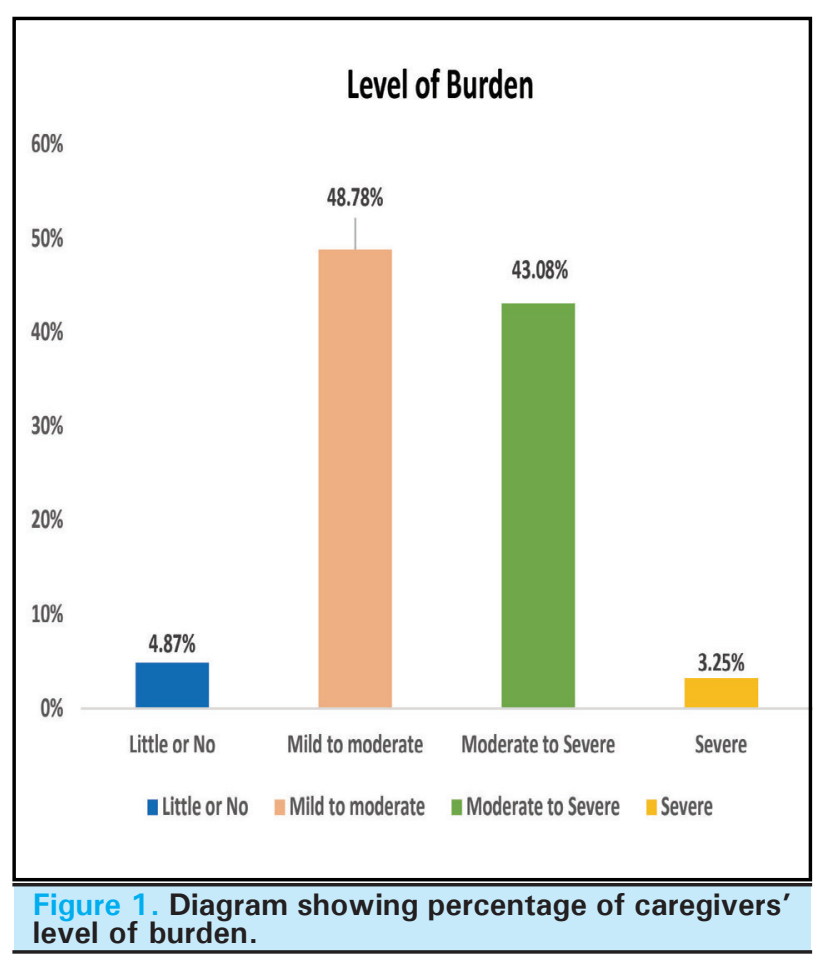




\section{DISCUSSION}

Caregivers of patient receiving hemodialysis feel more responsibilities and are at higher risk of developing emotional and psychological distress, low quality of life and increased burden. In spite of their daily obligations, they tend to fulfill the need of patients which sums up with the feeling of burden.

In this study majority of the caregivers are females $(57.72 \%)$. Since women being more willing to embrace caregiving roles can be attributed to women being more compassionate and emotional and being better in coping with the difficulties of caregiving. This finding is comparable to the finding of the study conducted in Turkey where majority of the caregivers were female. ${ }^{6}$ Similarly, the majority of the caregivers (56.09\%) were spouse in the relationship to the patient which is consistent to a study conducted in China which reveals that $93 \%$ of the caregivers were spouses. ${ }^{7}$ Maximum $47.15 \%$ of the caregivers belongs to more than 3 years of caregiving duration. It can be attributed as, the longer the caregivers took care of their patients, the greater burden they endured and the poorer mental health they had. ${ }^{8}$ In this study majority of the patients are older ( $\geq 60 \mathrm{yrs}$ ) which implies the patient to involve less in physical activities and are more likely to seek care from caregivers. Similar findings have been suggested by the study conducted in Jordan. ${ }^{9}$
In this study, most of the caregivers perceived mild to moderate burden $(48.78 \%)$. This findings were supported by the study conducted in Rawalpindi, Pakistan where $65 \%$ of the caregivers perceived mild to moderate burden. ${ }^{10}$ Studies done in different Asian countries also demonstrate similar findings. ${ }^{11,12}$

\section{CONCLUSIONS}

Caregivers may develop emotional and psychological distress, low quality of life, financial problems, increased workload, anger depression, a feeling of helplessness and then to an increased burden. Therefore, Coping Strategies, social support, support interventions should be planned to assist the caregivers in achieving their roles in caring the patients and increases the capability to cope effectively with the patient's condition.

\section{ACKNOWLEDGEMENTS}

We would like to thank College of Medical Sciences Teaching Hospital and Chitwan Medical College Teaching Hospital for the co-operation.

\section{Conflict of Interest: None.}

\section{REFERENCES}

1. Lewis, Dirksen, Heitkemper, Bucher . Lewis's Medical and Surgical Nursing, 2nd South Asia rev. ed. United States: Elsevier Publication; 2015.1169 p. [Full Text]

2. Wang H, Naghavi M, Allen C, Barber R, Bhutta Z, Carter A et al. A systematic analysis for the Global Burden of Disease Study 2015. Lancet. 2016;388(10053):1459-1544. [PubMed]

3. Valerie A Luyckx, Marcello Tonelli \& John W Stanifer (World Health Organization) The Global Burden of Kidney Disease and Sustainable Development Goals. Bulletin of WHO. 2018;96:414-22D. [ull Text]

4. Nagasawa H, Sugita I, Tachi T, Esaki H, Yoshida A, Kanematsu $\mathrm{Y}$ et al. The Relationship Between Dialysis Patients' Quality of Life and Caregivers' Quality of Life. Front Pharmacol. 2018 July 16;9:770. [ubMed]

5. Gatua M. The burden of care and health-related quality of life among caregivers of a patient undergoing maintenance hemodialysis at the renal unit of Kenyatta National Hospital, published on 2016. 2017. [Full Text]

6. Chang HY, Chiou CJ, Chen NS. Impact of mental health and caregiver burden on family caregivers' physical health. Arch Gerontol Geriatr. 2010;50:267-71. [PubMed]
7. Zhang R, Cui X, Zhuang H. The Burden for Caring Patients on Maintenance Hemodialysis is Influenced by Social and Demographic Factors. Gen Med (Los Angeles) [Internet]. 2016;4(6):1000281. [Full Text]

8. Mollaoglu M, Kayatas M, Yürügen B. Effects on caregiver burden of education related to home care in patients undergoing hemodialysis. Hemodial Int [Internet]. 2012;17(3):413-20. [PubMed]

9. Alnazly EK, Samara NA. The Burdens on Caregivers of Patients above 65 Years Old Receiving Hemodialysis: A Qualitative Study. Health Care Current Reviews. 2014;2(1):1000 118. [Full Text]

10. Usman Shah H, Atif I, Rashid F, Babar M, Arshad F, Qamar W, et al. Assessment of caregiver burden of patients receiving dialysis treatment in Rawalpindi. J Pak Med Assoc. 2017;67(10):1498-1501. [PubMed]

11. Nagarathnam M, Reddy KP, Anuradha B, Shivkumar V, Latheef SA. The Assessment of Caregiver Burden in Caregivers of Hemodialysis Patients at a Tertiary Care Hospital of Andra Pradesh. Indian J Nephrol. 2016 [cited 23 January];26(2):152-3. [ubMed] 
12. Jafari H, Ebrahimi A, Aghaei A, Khatony A. The relationship between care burden and quality of life in caregivers of hemodialysis patients. BMC Nephrol. 2018;19:321. [․
13. Shakya D, Tuladhar J, Poudel S. Burden and Depression among Caregivers of Hemodialysis Patients. Palliative Medicine \& Care. 2017 April 17;4(1):1-6. [Full Text]

This work is licensed under a Creative Commons Attribution 4.0 International License. The images or other third party material in this article are included in the article's Creative Commons license, unless indicated otherwise in the credit line; if the material is not included under the Creative Commons license, users will need to obtain permission from the license holder to reproduce the material. To view a copy of this license, visit http://creativecommons.org/licenses/by/4.0/ 